\title{
Coupling in the middle atmosphere related to the 2013 major sudden stratospheric warming
}

\author{
R. J. de Wit ${ }^{1}$, R. E. Hibbins ${ }^{1,2}$, P. J. Espy ${ }^{1,2}$, and E. A. Hennum ${ }^{1}$ \\ ${ }^{1}$ Norwegian University of Science and Technology (NTNU), Trondheim, Norway \\ ${ }^{2}$ Birkeland Centre for Space Science, Bergen, Norway \\ Correspondence to: R. J. de Wit (rosmarie.wit@ntnu.no)
}

Received: 30 October 2014 - Revised: 23 January 2015 - Accepted: 26 January 2015 - Published: 11 March 2015

\begin{abstract}
The previously reported observation of anomalous eastward gravity wave forcing at mesopause heights around the onset of the January 2013 major sudden stratospheric warming (SSW) over Trondheim, Norway $\left(63^{\circ} \mathrm{N}, 10^{\circ} \mathrm{E}\right)$, is placed in a global perspective using Microwave Limb Sounder (MLS) temperature observations from the Aura satellite. It is shown that this anomalous forcing results in a clear cooling over Trondheim about $10 \mathrm{~km}$ below mesopause heights. Conversely, near the mesopause itself, where the gravity wave forcing was measured, observations with meteor radar, $\mathrm{OH}$ airglow and MLS show no distinct cooling. Polar cap zonal mean temperatures show a similar vertical profile. Longitudinal variability in the high northern-latitude mesosphere and lower thermosphere (MLT) is characterized by a quasi-stationary wave- 1 structure, which reverses phase at altitudes below $\sim 0.1 \mathrm{hPa}$. This wave-1 develops prior to the SSW onset, and starts to propagate westward at the SSW onset. The latitudinal pole-to-pole temperature structure associated with the major SSW shows a warming (cooling) in the winter stratosphere (mesosphere) which extends to about $40^{\circ} \mathrm{N}$. In the stratosphere, a cooling extending over the equator and far into the summer hemisphere is observed, whereas in the mesosphere an equatorial warming is noted. In the Southern Hemisphere mesosphere, a warm anomaly overlaying a cold anomaly is present, which is shown to propagate downward in time. This observed structure is in accordance with the temperature perturbations predicted by the proposed interhemispheric coupling mechanism for cases of increased winter stratospheric planetary wave activity, of which major SSWs are an extreme case. These results provide observational evidence for the interhemispheric coupling mechanism, and for the wave-mean flow interaction believed to
\end{abstract}

be responsible for the establishment of the anomalies in the summer hemisphere.

Keywords. Meteorology and atmospheric dynamics (middle atmosphere dynamics)

\section{Introduction}

Sudden stratospheric warmings (SSWs) are dramatic dynamic events that influence the temperature, circulation and chemical composition of the winter polar middle atmosphere (e.g. Labitzke, 1981; Charlton and Polvani, 2007; Chandran et al., 2014; Gerber et al., 2012, and references therein). SSWs are understood to develop due to the interaction between vertically propagating planetary waves (PWs) and the stratospheric vortex (Matsuno, 1971), and are characterized, in a zonal mean sense, by a rapid warming of the wintertime polar stratosphere, and a weakening (minor SSW) or reversal (major SSW if the reversal extends to $60^{\circ} \mathrm{N}$ and $10 \mathrm{hPa}$ ) of the stratospheric vortex (e.g. Labitzke, 1981).

Due to their large effect on stratospheric zonal winds, SSWs are capable of altering filtering conditions for upwardpropagating gravity waves (GWs). Various modelling studies have shown eastward GW forcing anomalies at mesosphere and lower thermosphere (MLT) altitudes in relation to SSWs (e.g. Yamashita et al., 2010; Chandran et al., 2011, 2014; Limpasuvan et al., 2012), a result that has been confirmed by radar observations of GW forcing at mesopause heights during the 2013 major SSW (de Wit et al., 2014b). Model studies have shown this departure away from climatological wintertime westward GW forcing to be associated with the weakening or reversal of the wintertime residual circulation and associated cooling of the mesosphere during 
SSWs (e.g. Holton, 1983; Chandran et al., 2014). In addition to mesospheric cooling, the high-latitude MLT response to SSWs has been observed to be characterized by a reversal or weakening of the wintertime eastward winds, as well as enhanced PW activity (Hoffmann et al., 2002, 2007; Jacobi et al., 2003; Matthias et al., 2012). Similarly, modelling studies have shown zonal wind reversals and increased PW forcing at mesospheric altitudes associated with SSWs (Chandran et al., 2013; Limpasuvan et al., 2012).

However, the effect of SSWs is not confined to the winter polar region. Matthias et al. (2013) used observations as well as reanalysis data to study the latitudinal displacement of SSWs throughout the Northern Hemisphere middle atmosphere. Although in most cases disturbances related to SSWs are strongest over the polar region, these disturbances have been observed to shift to mid-latitudes, which has been linked to increased mid-latitude PW activity (Matthias et al., 2013). Fritz and Soules (1970) were the first to show, using satellite radiance observations, that SSWs are accompanied by a simultaneous cooling over the equatorial region as well as the summer hemisphere at stratospheric levels. This equatorial cooling in connection to SSWs has been observed to extend upward to the mesosphere by Shepherd et al. (2007). In the equatorial upper mesosphere (between 70$80 \mathrm{~km}$ ), Sridharan et al. (2010) observed a warming of 10$15 \mathrm{~K}$ in relation to the 2009 major SSW. Using an SSW composite generated with the specified dynamics version of the Whole Atmosphere Community Climate Model (WACCMSD), Chandran and Collins (2014) found a cooling equatorward of $40^{\circ} \mathrm{N}$ below $60 \mathrm{~km}$, and a warming above, which was seen to extend to the Southern Hemisphere low latitudes. In addition, Chandran and Collins (2014) found a dependence of this signal on the phase of the quasi-biennial oscillation (QBO). They found that westward propagating PWs penetrated across the equator in the upper stratosphere when the QBO in the lower stratosphere was in the westward (blocking) phase and the QBO signal in the upper stratosphere was in the eastward phase, as was first proposed by Espy et al. (1997). This penetration of PWs into the upper stratosphere caused reduced upwelling and hence the weaker cooling.

The current study builds upon the observations of de Wit et al. (2014b), who observed that zonal winds from the surface to $100 \mathrm{~km}$ reversed and GW forcing at $\sim 90 \mathrm{~km}$ peaked eastward over Trondheim, Norway $\left(63^{\circ} \mathrm{N}, 10^{\circ} \mathrm{E}\right)$, during the onset of the January 2013 major SSW. Here, meteor radar and $\mathrm{OH}$ airglow temperature observations over Trondheim are presented from December 2012-February 2013 in order to study the mesopause temperature response to this observed eastward GW forcing. Using Aura Microwave Limb Sounder (MLS) temperatures, the temperature response in the layers below the altitude of meteor radar and airglow observations is quantified. In addition, the longitudinal variability of middle atmospheric temperatures in a $15^{\circ}$ latitude band around Trondheim is quantified around the SSW onset. Subsequently, the latitudinal variability and temporal devel- opment of the temperature perturbations related to the major SSW are presented from the winter to the summer pole, and these results are discussed in light of the interhemispheric coupling mechanism suggested by modelling results (Becker and Fritts, 2006; Karlsson et al., 2009a; Körnich and Becker, 2010).

\section{Data and analysis}

Single station mesopause temperature data over Trondheim, Norway $\left(63^{\circ} \mathrm{N}, 10^{\circ} \mathrm{E}\right)$, have been obtained using an all-sky interferometric meteor (SKiYMET) radar as well as airglow measurements. The Trondheim meteor radar has been operational near-continuously since September 2012, and has previously been used to quantify the zonal wind, gravity wave momentum flux and gravity wave forcing during the January 2013 major SSW (de Wit et al., 2014b). The radar's peak power is $30 \mathrm{~kW}$, and the radar operates at a frequency of $34.21 \mathrm{MHz}$. Meteors are detected between about $70 \mathrm{~km}$ and $100 \mathrm{~km}$, with meteor count rates peaking at $\sim 90 \mathrm{~km}$. Further details on the Trondheim meteor radar can be found in de Wit et al. (2014a). Daily meteor radar temperatures are derived using the technique outlined in Hocking (1999), in which meteor trail decay time is used to determine the ambipolar diffusion coefficient $\left(D_{\mathrm{a}}\right)$. A scale-height analysis of $D_{\mathrm{a}}$ allows for the determination of absolute temperatures as well as their uncertainty at $\sim 90 \mathrm{~km}$ (Hocking, 1999; Hocking et al., 2001; Stober et al., 2012).

Two additional independent temperature measurements for the same location are obtained using optical observations of the hydroxyl $(\mathrm{OH})$ airglow spectra of two spectral bands in the near-infrared. These observations are taken to represent the average temperature over an $8 \mathrm{~km}$ thick layer of the atmosphere centred around $87 \mathrm{~km}$. Nightly (solar depression angle $>5^{\circ}$ ) high-resolution spectral measurements of the Meinel $(3,1)$ - and $(4,2)$-bands have been used to determine nightly mean temperatures using the method described in Espy and Stegman (2002, and references therein). The current analysis has been slightly modified, and corrects for scattered light by subtracting off a baseline rather than employing a separate model as outlined in Espy and Stegman (2002). Prior to operation during the 2012-2013 winter, the instrument was calibrated for spectral radiance by a radiance standard traceable to the National Institute of Standards and Technology (NIST) in October 2012.

Near-global lower and middle atmosphere temperature data are provided by the Earth Observing System Microwave Limb Sounder (EOS MLS) aboard NASA's Aura satellite. Aura orbits at $705 \mathrm{~km}$ altitude in a sun-synchronous orbit, with an inclination of $98^{\circ}$ and an orbit time of $100 \mathrm{~min}$ (Waters et al., 2006). The geographical latitude range covered by MLS each orbit ranges from $82^{\circ} \mathrm{S}$ to $82^{\circ} \mathrm{N}$ (Waters et al., 2006). The MLS instrument contains several radiometers to measure microwave emission by the atmosphere in different 
spectral regions. Radiance observations at $118 \mathrm{GHz}$ near the $\mathrm{O}_{2}$ spectral line are used to derive middle atmospheric temperatures (Waters et al., 2006; Livesey et al., 2011) using the retrieval algorithms as outlined in Livesey et al. (2006, and references therein).

The current study uses MLS version 3.3 temperature measurements between $100-0.001 \mathrm{hPa}$ and $82^{\circ} \mathrm{S}-82^{\circ} \mathrm{N}$ from December 2012-February 2013. The vertical resolution of the data changes from around $5 \mathrm{~km}$ at $100 \mathrm{hPa}$ to $3.6 \mathrm{~km}$ at $31.6 \mathrm{hPa}$, and increases again with increasing height to $6 \mathrm{~km}$ in the mesosphere (Livesey et al., 2011). A full discussion of the uncertainties and biases in the MLS data can be found in Schwartz et al. (2008).

Prior to further processing, the data have been screened following the criteria described in Livesey et al. (2011) to guarantee that no poor-quality data are used. After dividing the data in a latitude-longitude grid, the daily mean and standard deviation of the observations are calculated and all observations more than 3 standard deviations away from the mean are removed to filter out any outliers remaining in the processed data (McDonald et al., 2011). In order to ensure a reasonable number of observations are used within each daily average, the latitude-longitude grid is specified depending on the analysis performed (see the Results section for further details). Daily average temperatures are calculated, using the temperature weighted by the cosine of the latitude in order to account for the relative increase in measurement density when moving poleward (e.g. Mlynczak et al., 2000).

To study the temporal and longitudinal variability of the 2013 major SSW, the observed absolute MLS temperatures have been used. However, in order to investigate the latitudinal coupling during the SSW, temperature perturbations from the zonal mean temperatures have been calculated in $5^{\circ}$ latitude bands from $80^{\circ} \mathrm{N}-80^{\circ} \mathrm{S}$ for all available pressure levels between $100-0.001 \mathrm{hPa}$. In order to retain only the intraseasonal temperature perturbations, the seasonal cycle has been removed using a Butterworth filter with a 50-day highfrequency pass band.

\section{Results}

\subsection{Temperature profile over Trondheim during the SSW}

As shown in de Wit et al. (2014b), and reproduced in Fig. 1a, the mesopause GW forcing over Trondheim during the onset of the January 2013 major SSW peaked eastward. To balance this eastward forcing, the development of an equatorward residual circulation resulting in upwelling and (adiabatic) cooling in these regions is expected (e.g. Holton, 1983; Becker, 2012). To check this assumption, the mesopause meteor radar temperatures (black dots, $\sim 90 \mathrm{~km}$ ) and airglow temperatures ((3,1)-band red crosses; $(4,2)$-band blue dots, $\sim 87 \mathrm{~km}$ ) have been shown in Fig. $1 \mathrm{~b}$ for the same loca-

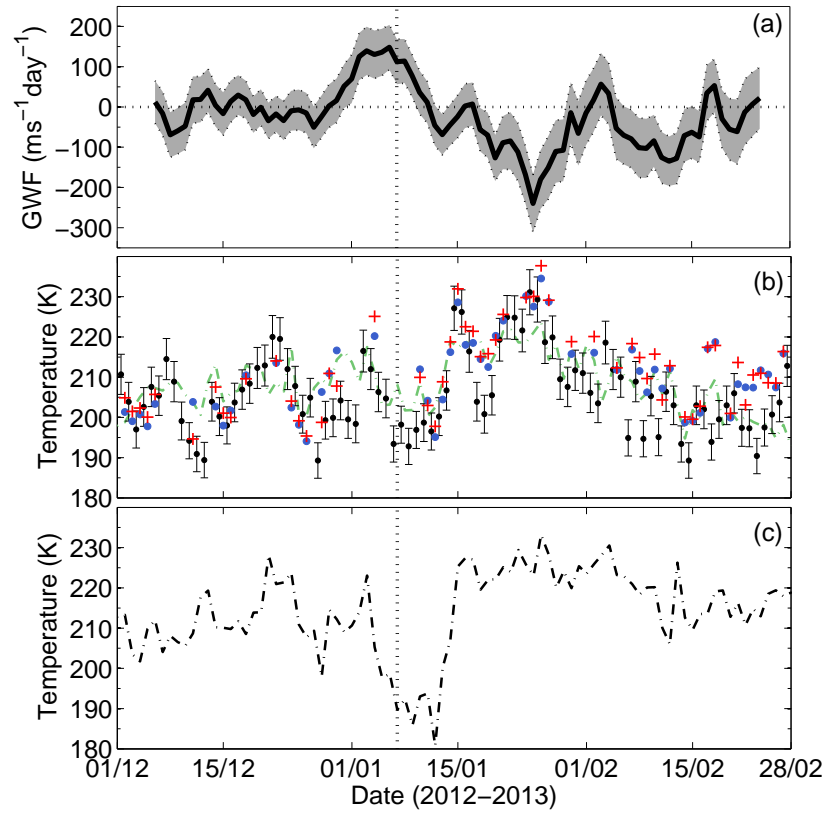

Figure 1. (a) 10-day moving average GW forcing (in $\mathrm{ms}^{-1}$ day $^{-1}$ at $\sim 90 \mathrm{~km}$ over Trondheim, derived from meteor radar observations (from de Wit et al., 2014b). (b) Trondheim meteor radar temperatures $(\sim 90 \mathrm{~km}$, black dots), Trondheim $\mathrm{OH}$ airglow temperatures ((3,1)-band, red crosses; (4,2)-band, blue dots, both $\sim 87 \mathrm{~km})$, and MLS temperatures in a $15^{\circ} \times 15^{\circ}$ area centred around Trondheim $(0.002 \mathrm{hPa}, \sim 86 \mathrm{~km}$, green dash-dotted line) for the 2012-2013 winter. (c) MLS temperatures in a $15^{\circ} \times 15^{\circ}$ area centred around Trondheim at $0.01 \mathrm{hPa}(\sim 79 \mathrm{~km})$. The onset of the major SSW on 7 January (defined as the day the zonal mean 4-day moving average zonal wind at $60^{\circ} \mathrm{N}, 10 \mathrm{hPa}$ reversed direction (de Wit et al., $2014 b)$ ) is indicated with a vertical dotted line.

tion and time period. Furthermore, the MLS temperatures in a $15^{\circ} \times 15^{\circ}$ area centred around Trondheim have been included (green dash-dotted line). The MLS pressure level under consideration is $0.002 \mathrm{hPa}$, which represents an approximate altitude of $86 \mathrm{~km}$ (based on CIRA-86 values, Fleming et al., 1990).

All four independent temperature measurements generally show good quantitative agreement. Throughout December 2012 the mesopause temperatures can be seen to oscillate between around 190 and $220 \mathrm{~K}$. Although mesopause temperatures right after the SSW onset are at the minimum of $190 \mathrm{~K}$, no clear mesopause cooling directly associated with the SSW onset is present. Rather, these low temperatures seem to be associated with the observed periodic oscillations in temperature and appear in no way distinct from the cold periods prior to the SSW. On the other hand, post-SSW during the second half of January, a mesopause warming is observed (Fig. 1b) at the same time the GW forcing over Trondheim turns westward (Fig. 1a).

Figure 1c shows the MLS temperatures for the same $15^{\circ} \times 15^{\circ}$ area centred around Trondheim, but at $0.01 \mathrm{hPa}$ 
$(\sim 79 \mathrm{~km})$. Throughout December the temperatures at $0.01 \mathrm{hPa}$ are generally comparable to the temperatures shown in Fig. 1b. However, 3 days prior to the SSW onset temperatures start to decrease, reaching minimum values of $\sim 180 \mathrm{~K}$ about one week after the SSW onset, demonstrating a clear cooling at this altitude over Trondheim related to the SSW.

\subsection{Polar cap zonal mean temperatures during the SSW}

To study the development of the temperature in the polar middle atmosphere during the 2012-2013 winter in more detail, the vertical profile of the polar cap zonal mean $\left(70-80^{\circ} \mathrm{N}\right)$ temperatures from MLS are shown in Fig. 2. Throughout December maximum temperatures of up to $270 \mathrm{~K}$ are located between 1 and $0.1 \mathrm{hPa}$, marking the stratopause. Around the beginning of January, the temperature maximum shifts downward, causing temperatures down to $100 \mathrm{hPa}$ to increase. These anomalously high temperatures last until the second half of January at $10 \mathrm{hPa}$. Concurrently, a mesospheric cooling is visible that maximizes at $0.01 \mathrm{hPa}$. It is also clear that the zonal mean temperatures do not show a cooling at $0.002 \mathrm{hPa}$ associated with the SSW. However, a warming post-SSW is visible, in accordance with the observations over Trondheim.

At the end of January, no clearly defined temperature maximum with height (i.e. a stratopause) appears to be present. An elevated stratopause (e.g. Orsolini et al., 2010) can be seen to reform just below $0.01 \mathrm{hPa}$ around the start of February, which propagates down to its pre-SSW altitude throughout February. During this elevated stratopause period, postSSW mesospheric temperatures have increased relative to their pre-SSW values. This course of events agrees well with the general temperature behaviour related to major SSWs with an associated elevated stratopause event (e.g. Chandran et al., 2014, and references therein), as well as with the temperatures presented for the 2013 major SSW as observed with the Solar Occultation for Ice Experiment onboard the Aeronomy of Ice in the Mesosphere satellite (Thurairajah et al., 2014).

\subsection{Zonal temperature structure at $63^{\circ} \mathrm{N}$ during the SSW}

Although the World Meteorological Organization defines SSWs in a zonal mean sense (weakening or reversal of the zonal mean eastward wind at $10 \mathrm{hPa}$; e.g. Charlton and Polvani, 2007), their effect in the stratosphere and mesosphere exhibits large zonal variability (e.g. Charlton and Polvani, 2007; Matthias et al., 2013). In order to study the longitudinal variability of the 2013 major SSW, Fig. 3 shows the longitudinal temperature distribution in a $15^{\circ}$ latitude band centred around Trondheim.

Pre-SSW a cold anomaly can be seen to develop in the MLT, with the maximum located in the Eastern Hemisphere.

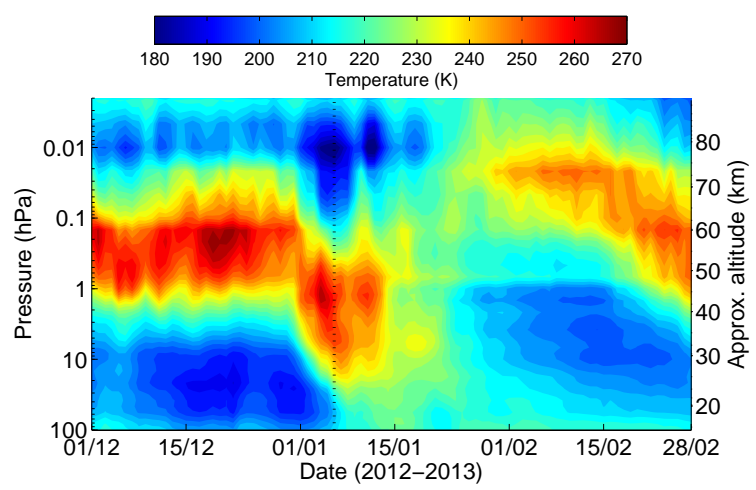

Figure 2. Polar cap zonal mean $\left(70-80^{\circ} \mathrm{N}\right)$ temperatures for the 2012-2013 winter. The approximate altitude scale has been derived using CIRA-86 data (Fleming et al., 1990). The onset of the SSW is indicated by a dotted line.

Trondheim is right on the western edge of this cold anomaly, until on the 7 January the cold anomaly starts to propagate westward over Trondheim. Around the 15 January the cold anomaly is located to the west of Trondheim and warmer temperatures have moved in overhead. This agrees with the airglow and meteor radar temperatures in Fig. 1, where the mesospheric warming over Trondheim that occurs after the SSW can be seen to begin on the same day. However, from Fig. 3 it becomes clear that this warming is only observed in the Eastern Hemisphere and that the cold anomaly is still present in the Western Hemisphere. Hence, Fig. 3 clearly illustrates that during the 2013 major SSW, large longitudinal variability is present in the stratosphere as well as mesosphere. Therefore, the behaviour seen in single station data will depend strongly on the position of the station relative to the wave structure, and should thus be interpreted with care (Jacobi et al., 2003; Chandran et al., 2014).

\subsection{Pole-to-pole middle atmosphere zonal mean temperature anomaly during the SSW}

SSWs are not exclusively high-latitude phenomena, and their effect has been shown to extend to mid- and low latitudes both in the stratosphere and MLT (e.g. Shepherd et al., 2007; Sridharan et al., 2010; Matthias et al., 2013; Chandran and Collins, 2014). To study the latitudinal extent of the temperature perturbations related to the 2013 major SSW in more detail, Fig. 4 shows a latitude-height cross-section of the 10-day average zonal mean temperature perturbation centred 9 days after the SSW onset.

From Fig. 4 it is clear that the SSW effect is not confined to the high-latitude winter pole. The stratospheric warm anomaly and MLT cold anomaly associated with the major SSW extend from polar regions down to mid-latitudes near $40^{\circ} \mathrm{N}$. In the stratosphere, the high-latitude warming is associated with a cooling that stretches out equatorward from $40^{\circ} \mathrm{N}$, over the equator and far into the summer hemisphere. 

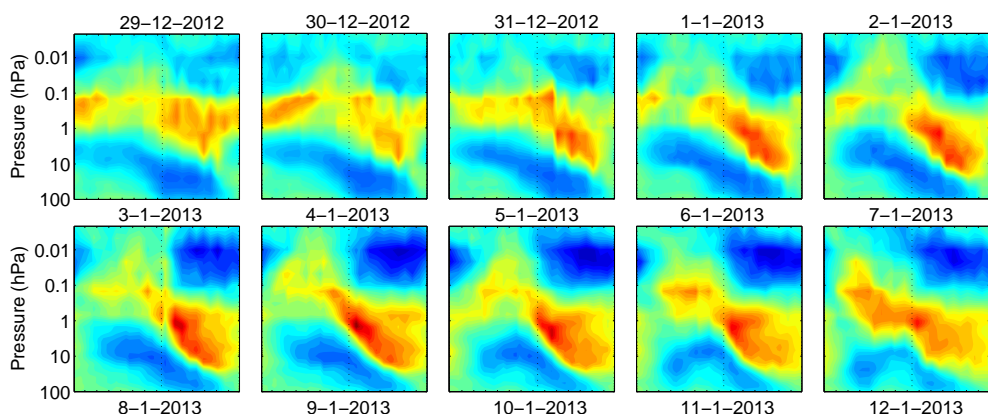

$6-1-2013$

$7-1-2013$
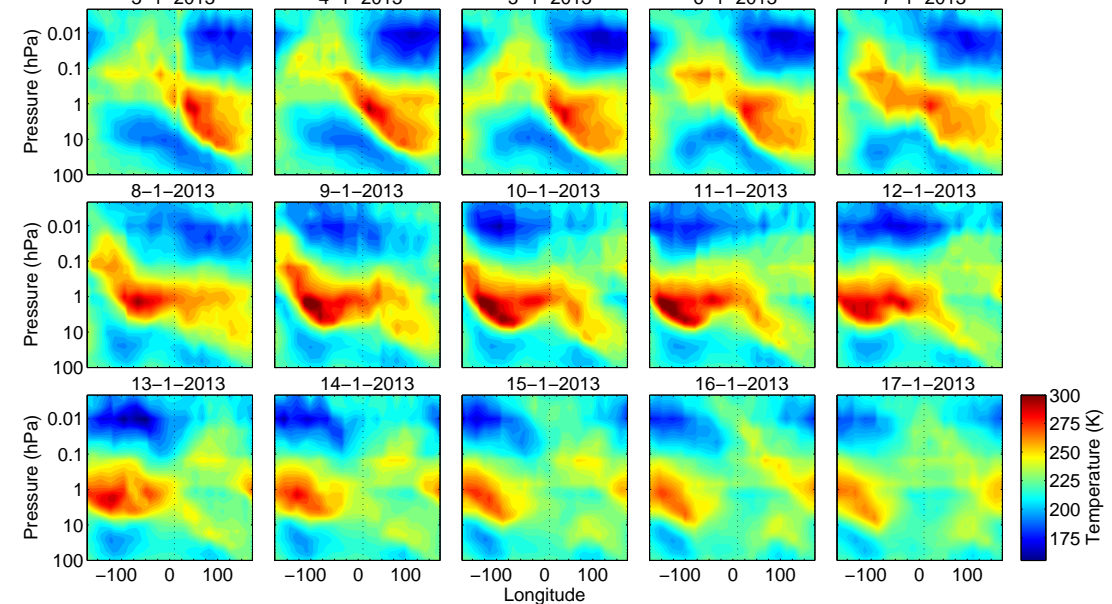

Figure 3. Longitudinal temperature distribution for a $15^{\circ}$ latitude band centred around $63^{\circ} \mathrm{N}$, from 29 December until 17 January. The temperatures have been determined for non-overlapping $15^{\circ}$ longitude bands between $-180^{\circ}$ (Western Hemisphere) and $180^{\circ}($ Eastern Hemisphere). The longitude of Trondheim has been highlighted with a dotted line. Note the difference in colour scale in comparison to Fig. 2. The SSW onset was on 7 January (de Wit et al., 2014b).

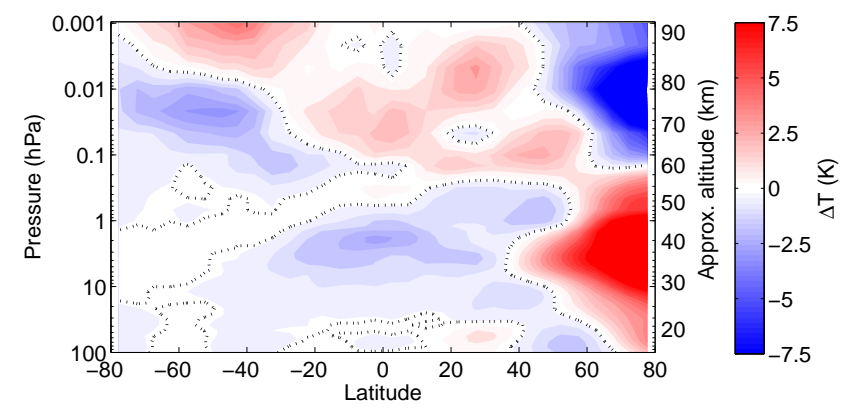

Figure 4. 10-day average zonal mean temperature anomaly shown for the middle atmosphere, centred 9 days after the SSW onset. The zero contour has been highlighted with a dotted line.

At altitudes above $\sim 0.1 \mathrm{hPa}$, a warm anomaly is observed between $40^{\circ} \mathrm{N}$ and $30^{\circ} \mathrm{S}$. Southward of this equatorial MLT warm perturbation, a temperature dipole with warmer temperatures overlaying cooler temperatures is present in the summer mesosphere and lower thermosphere. This dipole maximizes at around $50^{\circ} \mathrm{S}$, where the node is present at $\sim 0.01 \mathrm{hPa}$ (around $80 \mathrm{~km}$ ). The line of zero temperature anomaly slopes upward towards the pole, with cold temperature perturbations extending almost to the top of the domain at $80^{\circ} \mathrm{S}$.

\section{Discussion}

The mesopause GW forcing over Trondheim has been observed to turn eastward during the onset of the January 2013 major SSW (de Wit et al., 2014b, and Fig. 1a). Model results have shown mesospheric cooling associated with anomalous eastward GW forcing to develop in relation to SSWs (e.g. Holton, 1983). Although the combined meteor radar, airglow and MLS mesopause temperature observations presented here generally show good quantitative agreement, no mesopause cooling directly associated with this eastward GW forcing is observed (Fig. 1a and b). However, Fig. 1c shows that about $10 \mathrm{~km}$ lower, at $\sim 79 \mathrm{~km}$, MLS temperatures indicate a cooling around the SSW onset. Although the lack of cooling in relation to the eastward GW forcing at mesopause altitudes might seem remarkable, it can be explained in terms of downward control in that the mean steady-state vertical velocity at any level outside the tropics is related to the integrated amount of wave forcing in the column above that level (Haynes et al., 1991; Garcia and Randel, 2008). For example, in a ThermosphereIonosphere-Mesosphere-Electrodynamics General Circulation Model (TIME-GCM) study of GW parameter effects on mesosphere and thermosphere temperature behaviour during SSWs, Yamashita et al. (2010) noted mesospheric cooling occurred below the peak eastward GW forcing region. Hence, a GW forcing anomaly does not necessarily correspond to a cooling at the same altitude, and the behaviour 
depicted in Fig. 1 agrees well with the principle illustrated by Yamashita et al. (2010).

A temperature dependence on altitude similar to that shown in Fig. 1 was found by Siskind et al. (2005), who used Sounding of the Atmosphere with Broadband Emission Radiometry (SABER) satellite temperature observations validated with $\mathrm{OH}$ airglow temperatures to conclude that mesospheric temperatures between 0.7 and $0.01 \mathrm{hPa}$ showed a significant anticorrelation with stratospheric temperatures. Above $0.01 \mathrm{hPa}$ this correlation was seen to break down, which is in accordance with the lack of cooling observed between $\sim 86$ and $\sim 90 \mathrm{~km}$ over Trondheim. Following their result, Siskind et al. (2005) suggested that measurements between $\sim 83-90 \mathrm{~km}$ may not be representative of the entire mesosphere. However, Hoffmann et al. (2007) observed cooling to be associated with SSWs at those altitudes, using meteor radar temperature observations at Resolute Bay $\left(75^{\circ} \mathrm{N}, 95^{\circ} \mathrm{W}, \sim 90 \mathrm{~km}\right)$, Andenes $\left(69^{\circ} \mathrm{N}, 16^{\circ} \mathrm{E}\right.$, $\sim 90 \mathrm{~km})$ and Kühlungsborn $\left(54^{\circ} \mathrm{N}, 11^{\circ} \mathrm{E}, \sim 87 \mathrm{~km}\right)$. Considering these studies did not examine the same SSW, this suggests that the details of the vertical temperature structure change from event to event.

The presence of one cold cell in the mesosphere as seen in Fig. 3 suggests the existence of a planetary wave- 1 temperature structure, which is indicative of a vortex displacement type warming (e.g. Charlton and Polvani, 2007). To look into this planetary wave- 1 structure in more detail, Fig. 5a shows the amplitude of the wave-1 around the SSW onset in the stratosphere and mesosphere. In the mesosphere, the wave-1 strengthens until 2 days prior to the SSW onset and maximizes at $0.02 \mathrm{hPa}$. From Fig. $5 \mathrm{~b}$ it can be seen that the phase of this wave is relatively constant in time up until the SSW onset, indicating that the wave is quasi-stationary. Concurrently, an almost oppositely phased wave- 1 structure develops below $\sim 1 \mathrm{hPa}$. The phase-fronts of the warm anomaly below $\sim 1 \mathrm{hPa}$ increase with height as one moves towards the west, whereas the phase of the mesospheric cold anomaly appears to change less with altitude (see Fig. 3).

Similar PW behaviour has been noted by Liu and Roble (2002) while studying the coupling between the stratosphere and MLT during a self-generated SSW event in TIME-GCM. Their analysis indicated that planetary wave- 1 was the dominant wave component generated during the warming event. In addition, Liu and Roble (2002) showed the PWs in the stratosphere and MLT to be out of phase, which was attributed to in situ forcing of PWs in the MLT due to the nonzonally symmetric filtering of upward propagating GWs.

At the SSW onset, the wave-1 structure starts to propagate westward in both the stratosphere and mesosphere, and inspection of Fig. $5 \mathrm{~b}$ suggests the anomalies are approximately phase-locked. The westward propagation of the MLT wave number 1 post-SSW has been seen using SABER temperatures as well as in WACCM-SD simulations of a minor SSW in January 2012 (Chandran et al., 2013). During this latter event, Chandran et al. (2013) observed a westward propaga-
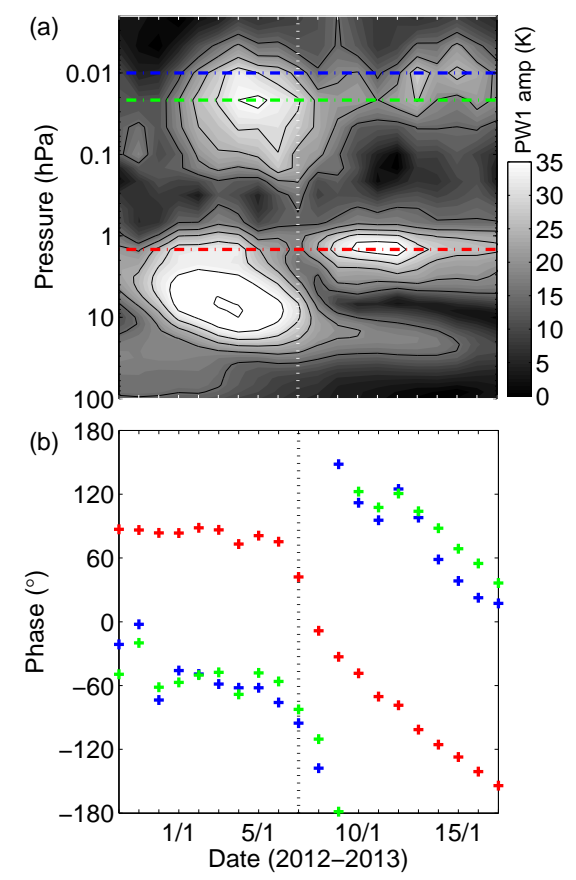

Figure 5. Planetary wave-1 amplitude (in K) from 29 December until 17 January. Contours highlight the 15 to $45 \mathrm{~K}$ levels, with intervals of $5 \mathrm{~K}$. Dash-dotted lines indicate (from top to bottom) the $0.01 \mathrm{hPa}$ (blue), $0.02 \mathrm{hPa}$ (green) and $1.5 \mathrm{hPa}$ (red) level. (b) Planetary wave- 1 phase (longitude $\left({ }^{\circ}\right)$ of maximum temperature) at $0.01 \mathrm{hPa}$ (blue crosses), $0.02 \mathrm{hPa}$ (green crosses) and $1.5 \mathrm{hPa}$ (red crosses). The onset of the SSW is indicated by a dotted line in both panels.

tion of the MLT wave number 1 starting 1 day prior to the SSW onset, although in the stratosphere between $40-50 \mathrm{~km}$ the PW remained quasi-stationary. In this case the behaviour was interpreted as in situ forcing of PWs in the MLT due to instabilities of the background zonal wind field (Chandran et al., 2013).

An additional mechanism causing PWs in the MLT could be upward PW propagation from the stratosphere (e.g. Smith, 2003). However, it must be noted that the wave-1 structures in the stratosphere and MLT are separated by a minimum in $\mathrm{PW}$ amplitude between $\sim 1$ and $\sim 0.1 \mathrm{hPa}$ as indicated in Fig. 5a. This would indicate that the PW in the MLT is not an extension of the stratospheric wave and suggests that the PW in the MLT is forced in situ (Liu and Roble, 2002; Chandran et al., 2013). However, based solely on these temperature observations it is not possible to draw any definite conclusions without detailed modelling to determine the source of the wave-1 in the MLT during the 2013 major SSW.

The temperature structure seen in Fig. 4 is very similar to the temperature anomalies modelled by Becker and Fritts (2006) (their Fig. 5a) and invoked in the interhemispheric coupling mechanism proposed by Becker and Fritts (2006), Karlsson et al. (2009a) and Körnich and Becker (2010) for the case of high PW activity in the winter stratosphere. In 
this interhemispheric coupling mechanism, hereafter referred to as "BKK mechanism" (following Murphy et al., 2012), PW anomalies in the winter stratosphere are coupled to summer MLT temperature perturbations following a sequence of meridional circulation anomalies that each give rise to temperature perturbations in different parts of the middle atmosphere. As major SSWs are a result of increased PW activity in the winter stratosphere (Matsuno, 1971), major SSWs and their associated temperature anomalies can be seen as a special case of the BKK mechanism (Körnich and Becker, 2010). In contrast to the numerous modelling studies investigating the BKK mechanism (Becker and Fritts, 2006; Karlsson et al., 2009a; Körnich and Becker, 2010), observational evidence for the pole-to-pole coupling is less common. Therefore, we will discuss the temperature anomalies observed during the 2013 major SSW and shown in Fig. 4 in light of this interhemispheric coupling mechanism in more detail.

The BKK coupling mechanism is triggered by increased PW activity in the winter stratosphere, which results in a warming of the winter polar stratosphere. This increased PW activity leads to a stronger Brewer-Dobson circulation resulting in stronger downwelling and thus heating in the polar stratosphere, and stronger upwelling and hence cooling in the equatorial region (e.g. Matsuno, 1971; Körnich and Becker, 2010, and references therein). This mechanism explains the stratospheric temperature structure present in Fig. 4, with a winter polar stratospheric warm anomaly and cooling equatorward of $40^{\circ} \mathrm{N}$. Such equatorial cooling in connection to warmings in the winter polar region was originally observed by Fritz and Soules (1970). Using a composite of all major SSWs between 1988-2010 simulated with the specified dynamics version of WACCM (WACCM-SD), Chandran and Collins (2014) showed a stratospheric cooling equatorward of $60^{\circ} \mathrm{N}$ to be associated with major SSWs.

At altitudes above $\sim 0.1 \mathrm{hPa}$ in Fig. 4 , a warm anomaly is observed between $40^{\circ} \mathrm{N}$ and $30^{\circ} \mathrm{S}$. This observed equatorial warming is coupled to the mesospheric cooling at polar latitudes through the introduction of a GW-driven residual circulation. Selective filtering of GWs in the anomalous westward stratospheric winds during a major SSW introduces an eastward GW forcing perturbation in the polar MLT (de Wit et al., 2014b), which is balanced by an equatorward residual circulation. This GW-driven residual circulation causes the observed cooling in the polar MLT, and warming in the equatorial mesosphere (e.g. Chandran and Collins, 2014; Chandran et al., 2014). The WACCM simulations presented by Chandran and Collins (2014) that have been discussed above for the stratosphere, also showed a warming of the mid-latitude and equatorial mesosphere. In addition, an equatorial warming between 70 and $80 \mathrm{~km}$ in connection to the 2009 major SSW was observed over Gadanki $\left(14^{\circ} \mathrm{N}\right)$ using lidar observations (Sridharan et al., 2010). However, our observations contrast with the result presented by Shepherd et al. (2007), who used WINDII, MLS (both aboard UARS), and SABER temperature satellite data to study the SSW effect on the mesospheric temperature field from $5-15^{\circ} \mathrm{N}$ and observed an equatorial mesospheric cooling in relation to stratospheric warmings.

Karlsson et al. (2009a) proposed a mechanism through which the low-latitude MLT warm anomaly seen in Fig. 4 can lead to a warm anomaly in the MLT of the summer pole. The warm anomaly in the equatorial mesosphere increases the meridional temperature gradient in the summer hemisphere, and a stronger increase of zonal wind with height compared to the climatological case occurs in the summer mesosphere at mid-latitudes, consistent with conservation of thermal wind balance. As a result, eastward GWs are filtered lower down in the increased zonal winds, resulting in a downward shift of the residual circulation (Becker and Fritts, 2006; Karlsson et al., 2009a). Associated with this downward shift, less dynamical cooling occurs in the region of reduced equatorward flow, leading to a warm anomaly (Karlsson et al., 2009a; Körnich and Becker, 2010). Below, the relative increase in GW forcing results in enhanced equatorward flow and an increase of dynamical cooling, and therefore a cold-temperature perturbation.

Indeed, summer temperatures at the top of the MLT are warmer, as can be seen from Fig. 4. Nine days after the SSW onset, this warming is maximized around $50^{\circ} \mathrm{S}$ and extends down to about $80 \mathrm{~km}$ at this latitude. It should be noted that this polar warm anomaly does not extend as far down as the low-latitude warm anomaly, which is in accordance with the model results (e.g. Becker and Fritts, 2006). Karlsson et al. (2009b) observed the effect of this increased summer mesopause temperature in relation to strong winter stratosphere PW activity as well, using polar mesospheric cloud occurrence frequency as a proxy for polar mesopause temperature. However, as this technique can only determine temperature changes in a thin layer, no vertical profiles were shown. In Fig. 4, the warm anomaly in the summer MLT can be seen to be associated with a cold anomaly below about $80 \mathrm{~km}$, creating a temperature dipole. This cold anomaly is not usually mentioned in relation to the BKK mechanism (see e.g. Fig. 1 in Körnich and Becker, 2010, where only a summer mesopause warm anomaly is included in the schematic of the mechanism). However, it is in accordance with a downward shift of the GW-driven residual circulation and has also been noted by Becker and Fritts (2006) who saw, using single station data over Andenes $\left(69^{\circ} \mathrm{N}\right)$, a cooling below about $82 \mathrm{~km}$ and warming above in connection to the 2002 SSW in the Southern Hemisphere.

To study the stability of the temperature structure induced by the BKK mechanism as shown in Fig. 4, the middle atmosphere temperature anomaly time series is correlated relative to the high-latitude winter mesosphere. The altitude of maximum mesospheric cooling $(0.01 \mathrm{hPa}$, see Fig. 2) was used as the reference in the correlations, and the time period, from 1 January-28 February 2013, was chosen to include the main perturbations caused by the SSW. The approach is similar to 


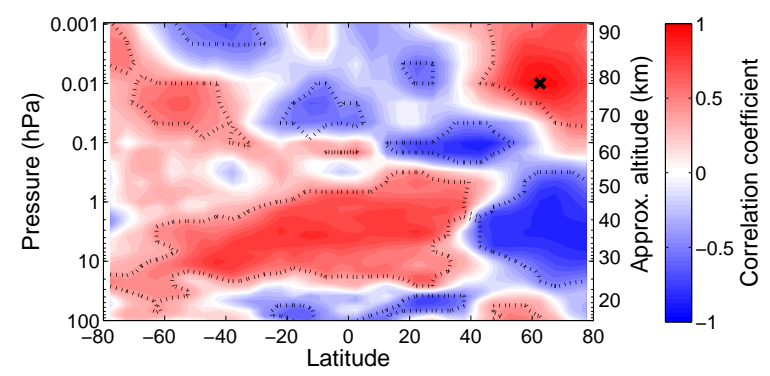

Figure 6. Correlation of middle atmosphere $\Delta T$ relative to $\Delta T$ at $63^{\circ} \mathrm{N}, 0.01 \mathrm{hPa}$ (region of maximum mesospheric cooling over Trondheim); $99 \%$ confidence level dotted, correlation baseline region indicated by a black cross.

that of $\mathrm{Xu}$ et al. (2009), except that in our study the winter mesosphere has been used as a baseline rather than the summer mesosphere.

The zero-lag result is shown in Fig. 6. In the winter MLT, the temperature anomalies are all positively correlated (depicted red) up to about $40^{\circ} \mathrm{N}$. The winter stratosphere is negatively correlated (depicted blue), indicating the temperature perturbations develop out of phase and illustrating that the warming in the stratosphere is associated with cooling in the MLT and vice versa. The low-latitude MLT as well as the summer mid- and high-latitude temperature perturbations at altitudes above $80 \mathrm{~km}$ are out of phase relative to the baseline. However, the mid- and high-latitude temperature perturbations below $80 \mathrm{~km}$, which constitute the lower branch of the temperature dipole, are positively correlated with the baseline.

Figure 6 looks very similar to Fig. 4 (note that the colours are reversed, reflecting the use of the winter high-latitude MLT as the baseline time series). Considering that the correlation time series spanned 1 January-28 February, this indicates that the BKK mechanism induced temperature variability in response to the mesospheric cooling and subsequent warming (i.e. the baseline behaviour) is stable and is the dominant mode of temperature variability throughout the whole middle atmosphere during this time period.

To investigate the development of the Southern Hemisphere response, Fig. 7a-c shows the 5-day mean middleatmosphere temperature anomalies between 80 and $30^{\circ} \mathrm{S}$, for three different time periods starting at the onset of the SSW, and 5 and 10 days later. At the SSW onset (panel a), a warm anomaly overlaying a cold perturbation is present in the mesosphere. Throughout the stratosphere, the equatorial cold anomaly extends to about $70^{\circ} \mathrm{S}$. Five days later (panel b), the stratospheric temperature anomalies are no longer present except for a limited region equatorward of $50^{\circ} \mathrm{S}$. In the MLT, the temperature dipole, expected from the downward shift in GW breaking altitude (Karlsson et al., 2009a), has intensified relative to the situation shown in panel a. As in panel a, the warm anomaly extends down to about $80 \mathrm{~km}$ closest to the equator. The warm anomaly gets shallower closer to the

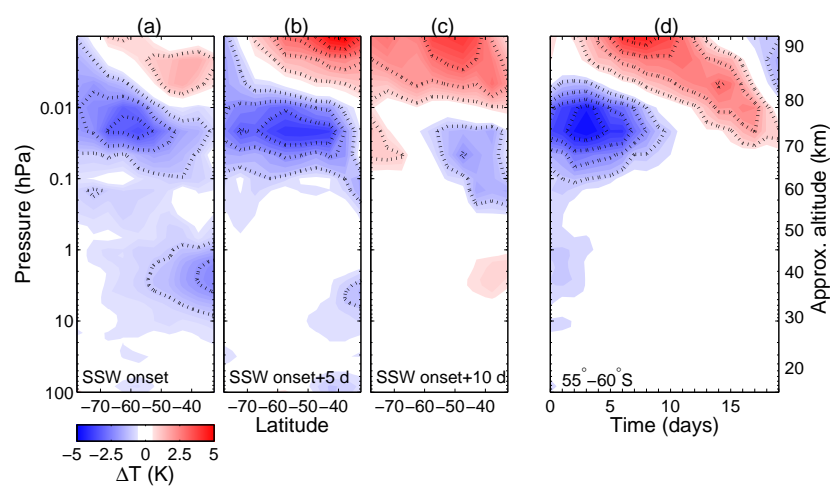

Figure 7. (a-c) Latitude-height cross-section of 5-day average temperature perturbations in the Southern Hemisphere, with averages starting at the day of the SSW onset, 5 days after the SSW onset, and 10 days after the SSW onset, respectively. (d) Time series showing the development of the 5-day moving average temperature perturbation at $55-60^{\circ} \mathrm{S}$. The time is indicated relative to the start of the SSW onset. The colour scale used in Fig. 7 is equal for all panels, and temperature anomalies with a magnitude smaller than $0.5 \mathrm{~K}$ are not shown for clarity. The $\pm 1, \pm 2, \pm 3, \pm 4$, and $\pm 5 \mathrm{~K}$ contours are highlighted with a dotted line.

pole, and disappears around $70^{\circ} \mathrm{S}$. After 10 days (panel c), the warm anomaly extends down to at least $80 \mathrm{~km}$ at all latitudes under consideration. The sequence of events shown in panels a-c suggests a direct warming in the Southern Hemisphere MLT (panel a), that strengthens and propagates poleward in time (panels b-c) following the major SSW.

Figure 8 in Karlsson et al. (2009a) shows the modelled GW forcing anomaly in the summer MLT in response to strong wintertime stratospheric PW events at different times during the coupling process, and upon inspection of their figure a similar structure is seen. In the anomalies presented in Karlsson et al. (2009a), a westward GW forcing anomaly (denoting a reduction in eastward GW forcing and thus a reduction in equatorward flow relative to the climatological state at this altitude, which is associated with warm perturbations) with its phase front slanting up towards the pole overlays an eastward GW forcing anomaly (associated with cold perturbations), and these anomalies can be seen to propagate poleward in time, just like the observed temperature anomalies presented in Fig. 7

As the Southern Hemisphere temperature dipole is thought to develop in response to a $\mathrm{GW} /$ mean-wind interaction, the temperature response is expected to propagate downward in time (Karlsson et al., 2009a). The model results of Karlsson et al. (2009a) indeed showed a downward propagation of the temperature anomalies. To provide observational evidence for the wave/mean-flow interaction as the mechanism responsible for the coupling from the equator to the summer hemisphere, the temporal development of the temperature anomalies between 55 and $60^{\circ} \mathrm{S}$ are shown in Fig. 7d. Again, the temperature dipole with warm overlaying cold anoma- 
lies is apparent. The warm anomaly is confined to above around $85 \mathrm{~km}$ up to day 5 , until at day 19 it has reached $70 \mathrm{~km}$. Clearly, the observed warm temperature anomaly propagates downward in time, supporting the notion that the observed temperature perturbations occur as a result of the wave/mean-flow interaction.

\section{Summary}

The current paper uses Aura MLS temperature observations to put the observations of de Wit et al. (2014b) in a global perspective - de Wit et al. showed the zonal wind over Trondheim $\left(63^{\circ} \mathrm{N}, 10^{\circ} \mathrm{E}\right)$ to reverse from eastward to westward from the surface to $100 \mathrm{~km}$ around the onset of the major SSW on 7 January 2013, and mesopause GW forcing to peak eastward. The expected response to this eastward GW forcing is a cooling (Holton, 1983). However, mesopause temperature observations obtained using meteor radar, $\mathrm{OH}$ airglow and MLS for the same location do not show a clear cooling in relation to the SSW. In contrast, temperatures over Trondheim measured by MLS at $\sim 79 \mathrm{~km}$ do show a distinct cooling around the SSW onset. This vertical structure has been attributed to downward control, and is reflected in a TIMEGCM study of the response of the mesosphere and thermosphere to GW forcing associated with SSWs, which showed maximum mesospheric cooling to occur below the area of peak eastward GW forcing (Yamashita et al., 2010).

Polar cap zonal mean temperatures derived from MLS data show that the temperature behaviour observed over Trondheim holds in a zonal mean sense, with maximum mesospheric cooling centred at around $0.01 \mathrm{hPa}(\sim 79 \mathrm{~km})$. PostSSW mesospheric warming is observed both over Trondheim and in the polar cap zonal mean, in agreement with the strong westward GW forcing present over Trondheim at this time. Although the temperatures observed over Trondheim agree well with the zonal mean behaviour, large longitudinal temperature variability is present at this station's latitude. Prior to the SSW onset, a quasi-stationary planetary wave- 1 develops below $\sim 0.1 \mathrm{hPa}$, whereas above this level a wave-1 structure of the opposite sign appears. At the SSW onset, these structures start to propagate westward and appear to be phase-locked. The existence of the PW in the mesosphere is thought to be forced in situ due to either non-zonally symmetric filtering of upward propagating GWs or instabilities in the zonal wind field, although based solely on these observations the two mechanisms cannot be distinguished.

Focusing on the latitudinal extent of the 10-day average of temperature perturbations centred 9 days after the SSW onset, the winter stratospheric warming and mesospheric cooling are seen to extend up to about $40^{\circ} \mathrm{N}$. The stratospheric warming is accompanied by cooling in the equatorial region and into the summer hemisphere. In the MLT, an equatorial warm anomaly is present, that splits into a dipole of warm overlaying cold perturbations when moving toward the sum- mer pole. This pole-to-pole temperature perturbation pattern can be interpreted in terms of the interhemispheric coupling mechanism (Becker and Fritts, 2006; Karlsson et al., 2009a; Körnich and Becker, 2010) as a response to enhanced winter stratosphere PW activity leading to the major SSW. Subsequent correlation analysis, relating winter mesosphere temperature perturbations to the rest of the middle atmosphere, shows that this feature is the main mode of temperature variability around the 2013 major SSW. The Southern Hemisphere response to this SSW is characterized by a temperature dipole, with warm temperature anomalies overlaying cold anomalies. The observed warm anomaly is seen to propagate downward in time, in agreement with GW/mean-flow interaction proposed by Karlsson et al. (2009a) to explain the summer MLT response to winter stratospheric PW activity.

Acknowledgements. We thank NASA for providing access to the Aura-MLS version 3.3 level 2 temperature data. This study was partly supported by the Research Council of Norway/CoE under contract 223252/F50.

Topical Editor C. Jacobi thanks two anonymous referees for their help in evaluating this paper.

\section{References}

Becker, E.: Dynamical Control of the Middle Atmosphere, Space Sci. Rev., 168, 283-314, doi:10.1007/s11214-011-9841-5, 2012.

Becker, E. and Fritts, D. C.: Enhanced gravity-wave activity and interhemispheric coupling during the MaCWAVE/MIDAS northern summer program 2002, Ann. Geophys., 24, 1175-1188, doi:10.5194/angeo-24-1175-2006, 2006.

Chandran, A. and Collins, R. L.: Stratospheric sudden warming effects on winds and temperature in the middle atmosphere at middle and low latitudes: a study using WACCM, Ann. Geophys., 32, 859-874, doi:10.5194/angeo-32-859-2014, 2014.

Chandran, A., Collins, R. L., Garcia, R. R., and Marsh, D. R.: A case study of an elevated stratopause generated in the Whole Atmosphere Community Climate Model, Geophys. Res. Lett., 38, L08804, doi:10.1029/2010GL046566, 2011.

Chandran, A., Garcia, R. R., Collins, R. L., and Chang, L. C.: Secondary planetary waves in the middle and upper atmosphere following the stratospheric sudden warming event of January 2012, Geophys. Res. Lett., 40, 1861-1867, doi:10.1002/grl.50373, 2013.

Chandran, A., Collins, R. L., and Harvey, V. L.: Stratospheremesosphere coupling during stratospheric sudden warming events, Adv. Space Res., 53, 1265-1289, doi:10.1016/j.asr.2014.02.005, 2014.

Charlton, A. J. and Polvani, L. M.: A new look at stratospheric sudden warmings. Part I: Climatology and modeling benchmarks, J. Climate, 20, 449-469, doi:10.1175/JCLI3996.1, 2007.

de Wit, R. J., Hibbins, R. E., and Espy, P. J.: The seasonal cycle of gravity wave momentum flux and forcing in the high latitude northern hemisphere mesopause region, J. Atmos. Sol.-Terr. Phy., online first, doi:10.1016/j.jastp.2014.10.002, 2014a. 
de Wit, R. J., Hibbins, R. E., Espy, P. J., Orsolini, Y. J., Limpasuvan, V., and Kinnison, D. E.: Observations of gravity wave forcing of the mesopause region during the January 2013 major Sudden Stratospheric Warming, Geophys. Res. Lett., 41, 4745-4752, doi:10.1002/2014GL060501, 2014b.

Espy, P. J. and Stegman, J.: Trends and variability of mesospheric temperature at high-latitudes, Phys. Chem. Earth, 27, 543-553, doi:10.1016/S1474-7065(02)00036-0, 2002.

Espy, P. J., Stegman, J., and Witt, G.: Inter-annual variations of the quasi-16-day oscillation in the polar summer mesospheric temperature, J. Geophys. Res., 102, 1983-1990, doi:10.1029/96JD02717, 1997.

Fleming, E., Chandra, S., Barnett, J., and Corney, M.: Zonal mean temperature, pressure, zonal wind, and geopotential height as functions of latitude, COSPAR International Reference Atmosphere: 1986, Part II: Middle Atmosphere Models, Adv. Space Res., 10, 11-59, 1990.

Fritz, S. and Soules, S. D.: Large-Scale Temperature Changes in the Stratosphere Observed from Nimbus III, J. Atmos. Sci., 27, 1091-1097, doi:10.1175/15200469(1970)027<1091:LSTCIT>2.0.CO;2, 1970.

Garcia, R. R. and Randel, W. J.: Acceleration of the Brewer-Dobson Circulation due to Increases in Greenhouse Gases, J. Atmos. Sci., 65, 2731-2739 doi:10.1175/2008JAS2712.1, 2008.

Gerber, E. P., Butler, A., Calvo, N., Charlton-Perez, A., Giorgetta, M., Manzini, E., Perlwitz, J., Polvani, L. M., Sassi, F., Scaife, A. A., Shaw, T. A., Son, S.-W., and Watanabe, S.: Assessing and Understanding the Impact of Stratospheric Dynamics and Variability on the Earth System, B. Am. Meteorol. Soc., 93, 845-859, doi:10.1175/BAMS-D-11-00145.1, 2012.

Haynes, P. H., Marks, C. J., McIntyre, M. E., Shepherd, T. G., and Shine, K. P.: On the "downward control" of extratropical diabatic circulations by eddy-induced mean zonal forces, J. Atmos. Sci., 48, 651-679, doi:10.1175/15200469(1991)048<0651:OTCOED>2.0.CO;2, 1991.

Hocking, W. K.: Temperatures using radar-meteor decay times, Geophys. Res. Lett., 26, 3297-3300, doi:10.1029/1999GL003618, 1999.

Hocking, W. K., Fuller, B., and Vandepeer, B.: Real-time determination of meteor-related parameters utilizing modern digital technology, J. Atmos. Sol.-Terr. Phy., 63, 155-169, 2001.

Hoffmann, P., Singer, W., and Keuer, D.: Variability of the mesospheric wind field at middle and Arctic latitudes in winter and its relation to stratospheric circulation disturbances, J. Atmos. Sol.Terr. Phy., 64, 1229-1240, doi:10.1016/S1364-6826(02)000718, 2002.

Hoffmann, P., Singer, W., Keuer, D., Hocking, W. K., Kunze, M., and Murayama, Y.: Latitudinal and longitudinal variability of mesospheric winds and temperatures during stratospheric warming events, J. Atmos. Sol.-Terr. Phy., 69, 2355-2366, doi:10.1016/j.jastp.2007.06.010, 2007.

Holton, J. R.: The Influence of Gravity Wave Breaking on the General Circulation of the Middle Atmosphere, J. Atmos. Sci., 40, 2497-2507, doi:10.1175/15200469(1983)040<2497:TIOGWB>2.0.CO;2, 1983.

Jacobi, Ch., Kürschner, D., Muller, H. G., Pancheva, D., Mitchell, N. J., and Naujokat, B.: Response of the mesopause region dynamics to the February 2001 stratospheric warming,
J. Atmos. Sol.-Terr. Phy., 65, 843-855, doi:10.1016/S13646826(03)00086-5, 2003.

Karlsson, B., McLandress, C., and Shepherd, T. G.: Interhemispheric mesospheric coupling in a comprehensive middle atmosphere model, J. Atmos. Sol.-Terr. Phys., 71, 518-530, doi:10.1016/j.jastp.2008.08.006, 2009a.

Karlsson, B., Randall, C. E., Benze, S., Mills, M., Harvey, V. L., Bailey, S. M., and Russell III, J. M.: Intra-seasonal variability of polar mesospheric clouds due to inter-hemispheric coupling, Geophys. Res. Lett., 36, L20802, doi:10.1029/2009GL040348, 2009b.

Körnich, H. and Becker, E.: A simple model for the interhemispheric coupling of the middle atmosphere circulation, Adv. Space Res., 45, 661-668, doi:10.1016/j.asr.2009.11.001, 2010.

Labitzke, K.: Stratospheric-Mesospheric Midwinter Disturbances: A Summary of Observed Characteristics, J. Geophys. Res., 86, 9665-9678, doi:10.1029/JC086iC10p09665, 1981.

Limpasuvan, V., Richter, J. H., Orsolini, Y. J., Stordal, F., and Kvissel, O.-K.: The roles of planetary and gravity waves during a major stratospheric sudden warming as characterized in WACCM, J. Atmos. Sol.-Terr. Phy., 78-79, 84-98, doi:10.1016/j.jastp.2011.03.004, 2012.

Liu, H.-L. and Roble, R. G.: A study of a self-generated stratospheric sudden warming and its mesospheric-lower thermospheric impacts using the coupled TIME-GCM/CCM3, J. Geophys. Res., 107, 4695, doi:10.1029/2001JD001533, 2002.

Livesey, N. J., Van Snyder, W., Read, W. G., and Wagner, P. A.: Retrieval algorithms for the EOS Microwave Limb Sounder (MLS), IEEE T. GRS., 44, 1144-1155, doi:10.1109/TGRS.2006.872327, 2006.

Livesey, N. J., Read, W. G., Froidevaux, L., Lambert, A., Manney, G. L., Pumphrey, H. C., Santee, M. L., Schwartz, M. J., Wang, S., Cofeld, R. E., Cuddy, D. T., Fuller, R. A., Jarnot, R. F., Jiang, J. H., Knosp, B. W., Stek, P. C., Wagner, P. A., and Wu, D. L.: EOS MLS Version 3.3 Level 2 data quality and description document, Tech. Rep. Version 3.3x-1.0, Jet Propulsion Laboratory, California Institute of Technology, Pasadena, California, 91198-8099, 2011.

Matsuno, T.: A Dynamical model of the Stratospheric Sudden Warming, J. Atmos. Sci., 28, 1479-1494, doi:10.1175/15200469(1971)028<1479:ADMOTS>2.0.CO;2, 1971.

Matthias, V., Hoffmann, P., Rapp, M., and Baumgarten, G.: Composite analysis of the temporal development of waves in the polar MLT region during stratospheric warmings, J. Atmos. Sol.-Terr. Phy., 90-91, 86-96, doi:10.1016/j.jastp.2012.04.004, 2012.

Matthias, V., Hoffmann, P., Manson, A., Meek, C., Stober, G., Brown, P., and Rapp, M.: The impact of planetary waves on the latitudinal displacement of sudden stratospheric warmings, Ann. Geophys., 31, 1397-1415, doi:10.5194/angeo-31-13972013, 2013.

McDonald, A. J., Hibbins, R. E., and Jarvis, M. J.: Properties of the quasi 16 day wave derived from EOS MLS observations, J. Geophys. Res., 116, D06112, doi:10.1029/2010JD014719, 2011.

Mlynczak, M. G., Garcia, R. R., Roble, R. G., and Hagan, M.: Solar energy deposition rates in the mesosphere derived from airglow measurements: Implications for the ozone model deficit problem, J. Geophys. Res., 105, 17527-17538, doi:10.1029/2000JD900222, 2000. 
Murphy, D. J., Alexander, S. P., and Vincent, R. A.: Interhemispheric dynamical coupling to the southern mesosphere and lower thermosphere, J. Geophys. Res., 117, D08114, doi:10.1029/2011JD016865, 2012.

Orsolini, Y. J., Urban, J., Murtagh, D. P., Lossow, S., and Limpasuvan, V.: Descent from the polar mesosphere and anomalously high stratopause observed in 8 years of water vapor and temperature satellite observations by the Odin Sub-Millimeter Radiometer, J. Geophys. Res., 115, D12305, doi:10.1029/2009JD013501, 2010.

Schwartz, M. J., Lambert, A., Manney, G. L., Read, W. G., Livesey, N. J., Froidevaux, L., Ao, C. O., Bernath, P. F., Boone, C. D., Cofield, R. E., Daffer, W. H., Drouin, B. J., Fetzer, E. J., Fuller, R. A., Jarnot, R. F., Jiang, J. H., Jiang, Y. B., Knosp, B. W., Krüger, K., Li, J.-L. F., Mlynczak, M. G., Pawson, S., Russell III, J. M., Santee, M. L., Snyder, W. V., Stek, P. C., Thurstans, R. P., Tompkins, A. M., Wagner, P. A., Walker, K. A., Waters, J. W., and Wu, D. L.: Validation of the Aura Microwave Limb Sounder temperature and geopotential height measurements, J. Geophys. Res., 113, D15S11, doi:10.1029/2007JD008783, 2008.

Shepherd, M. G., Wu, D. L., Fedulina, I. N., Gurubaran, S., Russell, J. M., Mlynczak, M. G., and Shepherd, G. G.: Stratospheric warming effects on the tropical mesospheric temperature field, J. Atmos. Sol.-Terr. Phy., 69, 2309-2337, doi:10.1016/j.jastp.2007.04.009, 2007.

Siskind, D. E., Coy, L., and Espy, P.: Observations of stratospheric warmings and mesospheric coolings by the TIMED SABER instrument, Geophys. Res. Lett., 32, L09804, doi:10.1029/2005GL022399, 2005.

Smith, A. K.: The origin of stationary planetary waves in the upper mesosphere, J. Atmos. Sci., 60, 3033-3041, doi:10.1175/15200469(2003)060<3033:TOOSPW>2.0.CO;2, 2003.

Sridharan, S., Raghunath, K., Sathishkumar, S., and Nath, D.: First results of warm mesospheric temperature over Gadanki $\left(13.5^{\circ} \mathrm{N}, 79.2^{\circ} \mathrm{E}\right)$ during the sudden stratospheric warming of 2009, J. Atmos. Sol.-Terr. Phy., 72, 1139-1146, doi:10.1016/j.jastp.2010.06.003, 2010.
Stober, G., Jacobi, C., Matthias, V., Hoffmann, P., and Gerding, M.: Neutral air density variations during strong planetary wave activity in the mesopause region derived from meteor radar observations, J. Atmos. Sol.-Terr. Phy., 74, 55-63, doi:10.1016/j.jastp.2011.10.007, 2012.

Thurairajah, B., Bailey, S. M., Yamashita Cullens, C., Hervig, M. E., and Russell III, J. M.: Gravity wave activity during recent stratospheric sudden warming events from SOFIE temperature measurements, J. Geophys. Res.-Atmos., 119, 8091-8103, doi:10.1002/2014JD021763, 2014.

Waters, J. W., Froidevaux, L., Harwood, R. S., Jarnot, R. F., Pickett, H. M., Read, W. G., Siegel, P. H., Cofield, R. E., Filipiak, M. J., Flower, D. A., Holden, J. R., Lau, G. K., Livesey, N. J., Manney, G. L., Pumphrey, H. C., Santee, M. L., Wu, D. L., Cuddy, D. T., Lay, R. R., Loo, M. S., Perun, V. S., Schwartz, M. J., Stek, P. C., Thurstans, R. P., Boyles, M. A., Chandra, K. M., Chavez, M. C., Chen, G.-S., Chudasama, B. V., Dodge, R., Fuller, R. A., Girard, M. A., Jiang, J. H., Jiang, Y., Knosp, B. W., LaBelle, R. C., Lam, J. C., Lee, K. A., Miller, D., Oswald, J. E., Patel, N. C., Pukala, D. M., Quintero, O., Scaff, D. M., Van Snyder, W., Tope, M. C., Wagner, P. A., and Walch, M. J.: The Earth Observing System Microwave Limb Sounder (EOS MLS) on the Aura satellite, IEEE T. GRS, 44, 1075-1092, doi:10.1109/TGRS.2006.873771, 2006.

Xu, X., Manson, A. H., Meek, C. E., Chshyolkova, T., Drummond, J. R., Hall, C. M., Riggin, D. M., and Hibbins, R. E.: Vertical and interhemispheric links in the stratosphere-mesosphere as revealed by the day-to-day variability of Aura-MLS temperature data, Ann. Geophys., 27, 3387-3409, doi:10.5194/angeo27-3387-2009, 2009.

Yamashita, C., Liu, H.-L., and Chu, X.: Responses of mesosphere and lower thermosphere temperatures to gravity wave forcing during stratospheric sudden warming, Geophys. Res. Lett., 37, L09803, doi:10.1029/2009GL042351, 2010. 